\title{
Cell-Nonautonomous Regulation of Proteostasis in Aging and Disease
}

\author{
Richard I. Morimoto \\ Department of Molecular Biosciences, Rice Institute for Biomedical Research, Northwestern University, \\ Evanston, Illinois 60208 \\ Correspondence: r-morimoto@northwestern.edu
}

The functional health of the proteome is determined by properties of the proteostasis network (PN) that regulates protein synthesis, folding, macromolecular assembly, translocation, and degradation. In eukaryotes, the PN also integrates protein biogenesis across compartments within the cell and between tissues of metazoans for organismal health and longevity. Additionally, in metazoans, proteome stability and the functional health of proteins is optimized for development and yet declines throughout aging, accelerating the risk for misfolding, aggregation, and cellular dysfunction. Here, I describe the cell-nonautonomous regulation of organismal PN by tissue communication and cell stress-response pathways. These systems are robust from development through reproductive maturity and are genetically programmed to decline abruptly in early adulthood by repression of the heat shock response and other cell-protective stress responses, thus compromising the ability of cells and tissues to properly buffer against the cumulative stress of protein damage during aging. While the failure of multiple protein quality control processes during aging challenges cellular function and tissue health, genetic studies, and the identification of small-molecule proteostasis regulators suggests strategies that can be employed to reset the PN with potential benefit on cellular health and organismal longevity.

$\mathrm{P}$ oteins exhibit an extraordinary diversity of sequence composition, conformational states, and properties, thus, keeping proteins optimally functional requires that the cell have robust quality control processes. Proteome health, therefore, requires a constant exchange between the intrinsic physical chemical properties of polypeptides and the cellular milieu in which they are expressed, folded, translocated, and degraded. These events are orchestrated by the proteostasis network (PN) that is comprised of ribosome quality control factors for protein syn-

thesis, molecular chaperones essential for coand posttranslational folding, transport processes and the degradative machineries of the ubiquitin-proteasome and the autophagy-lysosome pathways (Balch et al. 2008; Powers et al. 2009; Labbadia and Morimoto 2015b; Balchin et al. 2016; Deuerling et al. 2019; Jayaraj et al. 2019). For proteins to be functional, the PN needs to be stable and robust to diverse conditions of environmental and physiological stress by modulating protein synthesis rates, the activities and levels of molecular chaperones to prevent

Editors: Richard I. Morimoto, F. Ulrich Hartl, and Jeffery W. Kelly

Additional Perspectives on Protein Homeostasis available at www.cshperspectives.org

Copyright (C 2020 Cold Spring Harbor Laboratory Press; all rights reserved; doi: 10.1101/cshperspect.a034074

Cite this article as Cold Spring Harb Perspect Biol 2020;12:a034074 


\section{R.I. Morimoto}

misfolding and aggregation, and the properties of the degradative machines that recognize damaged and aggregated proteins for recycling (Fig. 1; Labbadia and Morimoto 2015b). Moreover, the constant challenge faced by the PN is to distinguish between sequence polymorphisms and biosynthetic errors that individually and collectively have modest effects on the normal flux of on-pathway intermediates when the $\mathrm{PN}$ is robust and functional from those changes in the amino acid sequence that interfere with folding stability. An imbalance in proteostasis causing or caused by an increase in metastable and nonproductive species leads to the loss-of-function or gain-of-function aggregation and proteotoxicity (Sormanni and Vendruscolo 2019). Protein misfolding is a constitutive property of biology because of the inherently error-prone nature of each step in gene expression. Added to this for nascent polypeptides is the highly crowded cellular environment that promotes nonnative interactions, the presence of intrinsically disordered regions, and the effects of posttranslational modifications that can affect protein conforma-

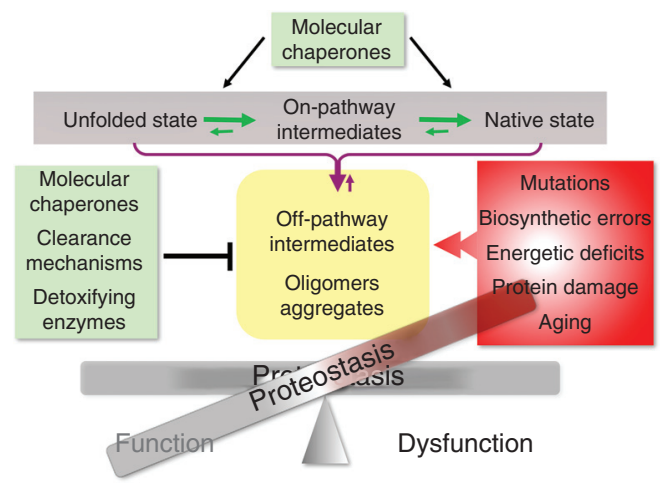

Figure 1. Role of the proteostasis network (PN) in protein quality control. The balance of on-pathway protein synthesis for native functional proteins and off-pathway intermediates prone for aggregation is determined by the interactions and functional properties of molecular chaperones and clearance mechanisms of the ubiquitin-proteasome and autophagy lysosomal machines. The robustness of the $\mathrm{PN}$ is challenged by mutations (polymorphisms) and error-prone synthesis, energetic deficits compromising ATP levels, and the effects of stress, aging, and cumulative damage. These events alter the balance of proteostasis. tion (Ellis and Minton 2006; Uversky et al. 2008). These intracellular events are then magnified by environmental stress conditions and physiological stimuli that can rapidly lead to altered composition or integrity of the proteome. These off-pathway events are counteracted by the ability of molecular chaperones to capture such intermediates for refolding and to resolve protein aggregates by the concerted activities of disaggregases and degradation pathways (Balchin et al. 2016; Deuerling et al. 2019; Jayaraj et al. 2019; Shorter and Southworth 2019). Expression of conformationally challenged proteins that persist as misfolded and aggregated species has consequences on the composition of all macromolecular machines with negative consequences on the fidelity of genetic information at the genomic, transcriptomic, and proteomic levels.

Thus, at the cellular level, the PN monitors the flux of protein synthesis and folding to promote functional folding and to minimize the accumulation of off-pathway intermediates that aggregate by selective disaggregation or degradation. To achieve this, the PN must have the capability to distinguish between the noise generated by coding region polymorphisms and biosynthetic errors from species that are kinetically unstable or become directed to alternate conformations in the folding landscape. Further, proteins are highly sensitive to fluctuations in the intracellular environment caused by shifts in energetics, $\mathrm{pH}$, oxidizing and reducing conditions, and the presence of a plethora of small molecules and metabolites that can affect folding and function. Added to these conditions are the effects of external stress caused by elevated temperatures or osmolytes that can have profound consequences on protein-folding thermodynamics, kinetics, and function. These intracellular and extracellular stress conditions, if not properly responded to, would be predicted to further amplify protein instability from sequence polymorphisms and biosynthetic errors that contribute to the stress of protein misfolding.

The ability of the PN to direct these events is dependent upon a core set of highly conserved proteins exemplified by molecular chaperones that exhibit a plethora of interactions with the 
proteome. Chaperones can function individually as holdases to interact with nascent and nonnative polypeptides in an ATP-independent manner to maintain the unfolded state and to prevent aggregation (Freeman and Morimoto 1996; Freeman et al. 1996; Balchin et al. 2016; Biebl and Buchner 2019; Deuerling et al. 2019; Jayaraj et al. 2019). Many of the ATP-dependent chaperones also function as holdases. Chaperone-dependent folding to the native state is an ATP-dependent process in which the nonnative client together with cochaperones of the J-domain family and nucleotide exchange factors direct each client polypeptide to the lowest free energy functional states. This process is directed by members of the Hsp40/J-protein cochaperone family, which direct substrate binding and the large family of Hsp70s (Kampinga and Craig 2010; Jayaraj et al. 2019). The disaggregase in plants and yeast is the $\mathrm{AAA}^{+}$protein, Hsp104, which is not conserved in other eukaryotes and this function is achieved by redirecting Hsp70s to disaggregation by interaction with Hsp110 or specific combinations of J-domain proteins (Nillegoda et al. 2015; Shorter and Southworth 2019). Molecular chaperones are also important in determining whether a client folds or should be degraded involving cochaperones of the tetratricopeptide repeat (TPR) domain family, such as CHIP (carboxyl-terminus of Hsp70 interacting protein). Together with the Hsp70/Hsp90 chaperones and the BAG-domain nucleotide exchange factors, clients are directed toward the ubiquitin-proteasome or autophagy-lysosomal machines (Finkbeiner 2019; Finley and Prado 2019; Morán Luengo et al. 2019). The function of molecular chaperones, therefore, is to serve in multiple hubs to direct the dynamic properties of the proteome in each subcellular compartment (Labbadia and Morimoto 2015b).

Proteostasis at the organismal level has additional levels of regulatory control (van Oosten-Hawle and Morimoto 2014; Li et al. 2017; Sala et al. 2017). For metazoans there is the challenge of diverse tissues with highly specialized function with distinct proteome composition and exposures to cell stress conditions. Muscle cells and neurons are examples of tissues with expressed proteomes with different properties, therefore the risk for damage from an imbalanced proteome may not be the same. For example, muscle cells express the highly abundant myofilament proteins titan and myosin at millions of copies per cell; consequently, errors in folding stability generated by polymorphisms or mutations could generate a disproportionate number of damaged molecules that are resolved when the PN is robust but during aging could overwhelm the capacity of the quality control machinery. To compensate for such an imbalance, metazoans employ intertissue communication to ensure that proteome failure within one tissue does not cause organismal failure (Garcia et al. 2007; Prahlad et al. 2008; Prahlad and Morimoto 2011; Silva et al. 2013; van Oosten-Hawle et al. 2013).

This review will address how metazoan tissues respond to proteotoxic stress throughout development into adulthood and aging, and how cell stress signals are communicated between tissues by cell-nonautonomous control to enhance the protective benefits of the heat shock response (HSR) and other cell stress responses to achieve cellular health, stress resilience, and longevity. The ability to detect and protect against environmental stress conditions is a prominent determinant for organismal fitness, therefore having a robust HSR and other cell stress responses are essential for metazoans to survive challenges that cannot be predicted. The HSR (Fig. 2) and other cell stress responses are therefore broadly relevant for environmental stress, during growth and development, in diverse forms of pathophysiology, and in a wide range of protein conformational diseases of aging.

\section{ROLE OF HSF1 IN THE HEAT SHOCK RESPONSE, STRESS RESILIENCE, AND PROTEOSTASIS}

In addition to being highly stress responsive, many of the heat shock genes are also ubiquitously expressed during cell growth and/or specifically required in development for tissuespecific needs and to protect against proteotoxic stress (Morimoto 1998, 2008, 2011; Åkerfelt et al. 2010; Guisbert et al. 2013; Li et al. 2017). Upon exposure to acute heat shock, the HSR is 
The heat shock response

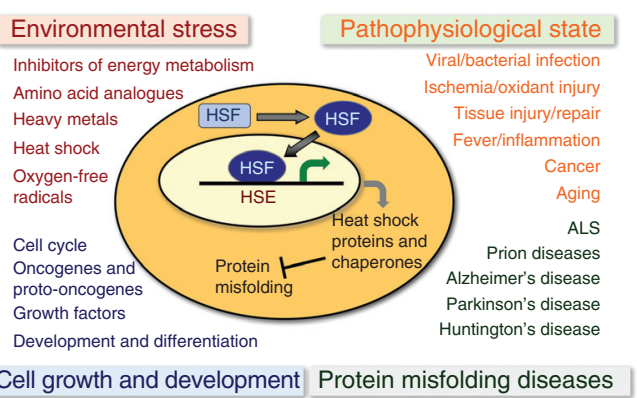

Figure 2. Regulation of the heat shock response (HSR). Diverse cellular conditions that induce the HSR include environment stress conditions, pathophysiological states associated with diseases, protein misfolding diseases with an emphasis on neurodegeneration and conditions of cell growth and differentiation. For many of these cellular states the induction of heat shock proteins and chaperones is mediated by heat shock transcription factor 1 (HSF1). HSE, Heat shock element; ALS, amyotrophic lateral sclerosis.

induced almost instantaneously within most, if not all, cells by the elevated expression of heat shock proteins (HSPs) proportional to the intensity, duration, and type of stress (Abravaya et al. 1991a,b,c; Gasch et al. 2000; Mahat et al. 2016; Joutsen and Sistonen 2018). While the primary response to heat shock is most often studied at the level of transcriptional control, heat shock affects nearly all aspects of gene expression and cellular function, including the effects of cell stress on messenger RNA (mRNA) subcellular localization and stability, translational control and effects on protein localization and turnover, and the dynamics of stress granules (Banerji et al. 1984; Theodorakis and Morimoto 1987; Labbadia and Morimoto 2015b; Vihervaara et al. 2018).

The stress-induced transcription of heat shock genes is regulated primarily by heat shock transcription factor 1 (HSF1), which is essential for the HSR and the inducible expression of the molecular chaperones, including Hsp70, Hsp90, Hsp110, and a subset of the J-domain cochaperones (Joutsen and Sistonen 2018). HSF1 is the founding member of the family of the HSF gene family (HSFs 1-4), which is conserved among eukaryotes (Sistonen et al. 1992; Wu 1995;
McMillan et al. 1998; Morimoto 1998, 2008; Kallio et al. 2001; Fujimoto et al. 2004; Åkerfelt et al. 2010). In addition to its role in acute and chronic stress, and in response to other perturbations of cellular physiology, HSF1 is also essential for pathways that promote longevity. Consequently, HSF1 has increasingly been implicated in many diseases most notably in cancer and neurodegenerative diseases (Fig. 2; Mendillo et al. 2015; Joutsen and Sistonen 2018; Lam et al. 2019).

HSF1 is constitutively expressed and, under conditions of heat shock, exhibits inducible DNA-binding activity from a stress-sensitive DNA-binding inactive state to a DNA-binding competent transcriptionally active state (Fig. 3). The inert HSF1 state is maintained by transient interactions with the molecular chaperones Hsp70 and the J-domain cochaperone Hdj-1 to keep HSF1 functionally repressed (Abravaya et al. 1992; Shi et al. 1998; Zou et al. 1998; Krakowiak et al. 2018). Activation to the transcriptionally active trimer that binds to heat shock elements (HSEs) positioned upstream of genes encoding molecular chaperones and other components of the PN causes the release of the paused RNA polymerase II resulting in their inducible transcription. Attenuation of the HSR at the transcriptional level, likewise, involves multiple steps, including silencing of HSF1 by binding of the chaperones Hsp70 and Hdj-1 (J-domain cochaperone) to the transactivation domain (Abravaya et al. 1992; Shi et al. 1998; Krakowiak et al. 2018), release of HSF1 from the HSEs by the reversible action of the acetyltransferase p300/CBP and the NAD-dependent deacetylase SIRT1, in addition to the deacetylases HDAC7 or HDAC9 that affect the occupancy of HSF1 on DNA and conversion of HSF1 trimers to the monomeric state (Westerheide et al. 2009; Zelin and Freeman 2015). The tight relationship between chaperone levels and their functional requirements and HSF1 activity reveals that the response to heat shock stress is proportional to the intensity and duration of the cell stress signal to ensure that the levels of chaperones induced are proportional to the amount of nonnative proteins.

HSF1 activity is also influenced by growth factors and cell stress signaling and nutrient- 


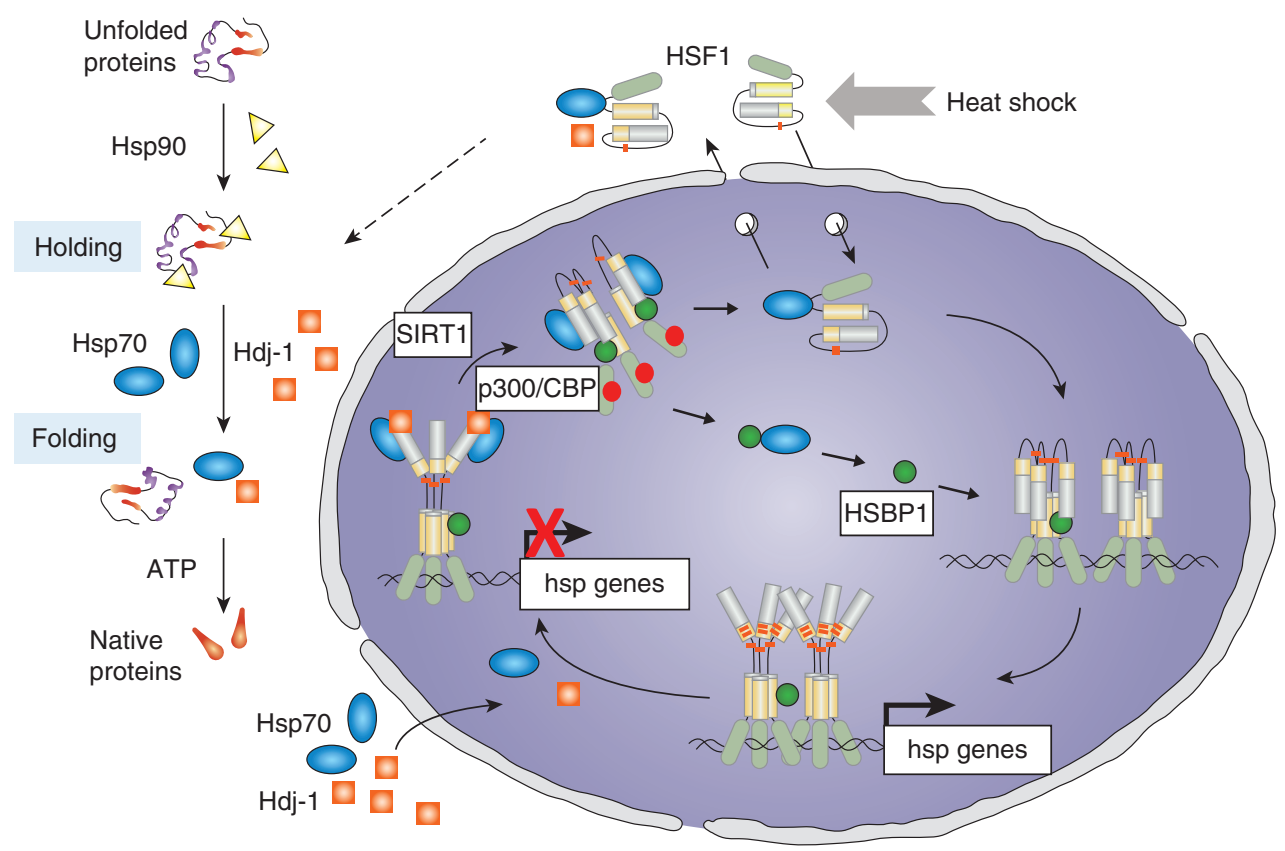

Figure 3. The heat shock transcription factor 1 (HSF1) cycle. Regulation of HSF1 in the heat shock response is titrated to protein quality control and the ratio of unfolded polypeptides that are stress sensitive and the requirements for cytoplasmic molecular chaperones Hsp70, J-domain cochaperones Hdj-1, and Hsp90 for folding. HSF1 persists in an inert state (either cytoplasmic or nuclear) associated with Hsp70 and Hdj-1 until these chaperones are titrated by the flux of unfolded proteins. HSF1 forms homotrimers that bind to heat shock elements in the promoters of genes encoding molecular chaperones and other components of the proteostasis network $(\mathrm{PN})$ and is posttranslationally modified by phosphorylation, sumoylation, and acetylation that affect transcriptional activity and DNA binding. Attenuation of the heat shock response involves chaperone-dependent silencing of the transactivation domain of HSF1, acetylation of the DNA-binding domain causing release from DNA and conversion to the monomer.

sensing pathways, revealing that the regulation of HSF1 and the HSR are linked to the proliferative and metabolic states of the cell (Li et al. 2017; Joutsen and Sistonen 2018). Associated with each step in the HSF1 cycle are a number of signaling pathways including the protein kinase MEK in the RAS/MAPK pathway that phosphorylates HSF1 at Ser326 to promote HSF1 nuclear translocation (Tang et al. 2015). Sumoylation of HSF1 on lysine 298 is influenced by phosphorylation on serines 303 and 307 to inhibit the HSR (Hietakangas et al. 2003; Anckar et al. 2006) and stress-inducible phosphorylation at HSF1 residues S230, S326, and S419 are suggested to serve as a rheostat of transcriptional activity (Knauf et al. 1996; Kline and Morimoto 1997; Holmberg et al. 2001; Guettouche et al. 2005; Westerheide et al. 2009; Åkerfelt et al.
2010). Further, the turnover of nuclear HSF1 is affected by the E3 ubiquitin ligase FBXW7 (Kourtis et al. 2015), which also controls the levels of multiple cell cycle regulators including cyclin E (Wang et al. 2012). Ubiquitylation of HSF1 by FBXW7 is primed by phosphorylation of HSF1 at Ser303 and Ser307 by GSK3 $\beta$ and ERK1 kinases, respectively (Chu et al. 1996; Knauf et al. 1996; Kourtis et al. 2015), which are involved in growth factor signaling. Collectively, these observations reveal that cell proliferation and the demands for protein synthesis are directly coordinated via HSF1 to prevent misfolded species from persisting in the cell.

In addition to the effects of cell proliferation on HSF1 activity are the effects of cell stress on metabolism. As primary human fibroblasts undergo replicative senescence, the HSR declines 


\section{R.I. Morimoto}

and this is mechanistically linked to reduced levels of the $\mathrm{NAD}^{+}$-dependent lysine deacetylase SIRT1 that is essential to maintain HSF1 in a DNA-binding competent state. Therefore, when the levels of SIRT1 decline, HSF1 is in the acetylated state that cannot bind to HSEs thereby causing attenuation of the HSR (Westerheide et al. 2009; Raychaudhuri et al. 2014). Additional evidence for the effects of the metabolic state on HSF1 regulation is the role of AMP-activated protein kinase (AMPK) that phosphorylates HSF1 at Ser121 in conditions of metabolic stress thus restricting nuclear entry of HSF1 (Dai et al. 2015). AMPK also has indirect effects on the HSR through the substrate PGC- $1 \alpha$, a regulator of mitochondrial biogenesis that interacts with HSF1 during fasting in mouse livers and primary hepatocytes (Minsky and Roeder 2015), thereby repressing the HSR when energy availability is low. Other roles for HSF1 in energy metabolism are to promote expression of PGC-1 $\alpha$ in brown adipose tissue (BAT), inguinal white adipose tissue, and skeletal muscle by regulating the expression of genes for mitochondrial function and maintenance of BAT to ameliorate metabolic dysfunction. HSF1 can also be inactivated by amino acid deprivation (Hensen et al. 2012). mTORC1 is a key regulator of translation that depends on amino acid levels, which promotes HSF1 activity through phosphorylation at Ser326 (Chou et al. 2012). These findings reveal an increasingly complex regulatory network of metabolites including $\mathrm{NAD}^{+} / \mathrm{NADH}, \mathrm{AMP} /$ ATP and amino acid levels to titrate HSF 1 activity and the HSR according to energy availability and protein biogenesis. The multiple states of HSF1 could therefore reflect the necessity for HSF1 to be partially primed for activation, and subsequently induced according to the magnitude and persistence of the cell stress signal and with a range of feedback loops that allow for a precise regulation of chaperone levels in the cell. These findings together with the observation that the HSR is dampened in metabolic stress, reveals that HSF1 activity is linked to both energy availability and expenditure in a wide range of cellular states, and that HSF1 influences and is influenced by oscillations in the metabolic demands of different tissues and cell types.

\section{DEVELOPMENTAL CONTROL OF THE PN AND TISSUE-SPECIFIC RESPONSES OF HSF1 AND THE HSR}

The HSR has been described as a universal cell stress response, yet there have been intriguing observations where induction of the HSR was not detected or observed as a dampened response. Some examples include early mouse development and expression in the brain of animals exposed to whole body stress (Bensaude et al. 1983; Bienz 1984a,b) and in different regions of the mouse brain (Sprang and Brown 1987; Blake et al. 1991; Shamovsky and Gershon 2004). These observations extend to human neuroblastoma Y79 cells that exhibit a selective response to heat shock with inducible transcription observed for Hsp90 but not the Hsp70 genes (Mathur et al. 1994). Related to this, primary hippocampal neurons from neonatal rat embryos did not exhibit an HSR, whereas primary astrocytes isolated from the same brain tissues exhibited a robust HSR, which appears to be the result of the selective expression of only HSF2 and not HSF1 in neurons compared to the astrocytes that expressed both HSFs (Marcuccilli et al. 1996). Similar observations with primary rodent motor neurons also observed a deficient HSR with partial activation of HSF1 (Batulan et al. 2003).

In contrast to vertebrates that express multiple HSF genes, Drosophila and Caenorhabditis elegans express only a single HSF1 gene, which is essential for development in addition to its canonical role for the HSR and other stress responses. In vertebrates, HSF1 has a role as a maternal factor for murine gametogenesis and regulates gene expression in the meiotic cell cycle. During development in C. elegans, HSF1 is essential and directs a pro-growth transcriptional program that is not a variant of the HSR, but rather corresponds to a genetic program that is coregulated with the cell cycle factor E2F/DP (Li et al. 2016). Expression of the Hsc70 and Hsp90 genes in development requires the partnership between E2F/DP and HSF1 and development-specific combinations of promoter elements that are distinct from the HSEs required for the HSR, and underscores the growth 
control program for protein quality control. Deletion of these development-specific elements impairs only developmental control and not the HSR and likewise, deletion of the HSR specific HSEs only impairs the HSR of the reporter. This strategy, pairing transcription factors for the HSR with the cell cycle, ensures that key molecular chaperones are expressed during development without compromising the HSR ( $\mathrm{Li}$ et al. 2017).

At the organismal level, the HSR is regulated by a network of 59 genes corresponding to positive activators (seven genes) required for the HSR and negative regulators (52 genes) whose knockdown lead to the constitutive activation of the HSR (Guisbert et al. 2013). These modifiers function in specific steps of gene expression, protein synthesis, protein folding, trafficking, and protein clearance. For example, the positive regulators are expressed in all tissues of C. elegans, whereas the negative regulators were mostly tissue-selective such that genetic knockdown of the subunits of the proteasome strongly induces heat shock reporter expression only in the intestine and spermatheca but not in muscle cells, while knockdown of subunits of the TRiC/CCT chaperonin induces heat shock reporter expression only in muscle cells. Yet, both the proteasome and TRiC/CCT chaperonin are ubiquitously expressed and are required for clearance and folding in all tissues. Moreover, knockdown of the positive regulators of the HSN are predicted to cause early-onset polyQ aggregation, and indeed, five of the seven positive HSR regulators have this phenotype, and knockdown of each enhances polyQ aggregation. In contrast, genes that are negative regulators of chaperone expression are both tissue-selective and chaperone specific and suggests that different tissues with distinctive proteome composition and function have tissue-selective responses to proteostasis disruption (Bar-Lavan et al. 2016). The paradigm for the regulation of HSF1 in the HSR has focused attention on the negative feedback loops of the HSP70 and J-domain chaperones, yet a larger network of at least 59 genes can regulate the expression of heat shock genes. Many of these genes have been previously linked to HSR regulation in other systems, including prokary- otes, suggesting that this regulatory network is conserved through evolution.

\section{INTEGRATION OF HSF1 TOGETHER WITH OTHER CELL STRESS RESPONSES AT THE ORGANISMAL LEVEL}

Despite the impressive capacity of the PN to buffer off-pathway events, the inability of different arms of the PN to respond appropriately in aging in the face of chronic proteotoxic stress, and challenged further by bouts of acute cell stress results in PN nonresponsiveness and cellular dysfunction. Under optimal biological conditions where the PN is highly dynamic, the level and balance of individual components are rapidly adjusted to compensate for changes in proteostatic load. This is accomplished by the coordinated activities of a suite of cell stress responses, including the HSR, the unfolded protein responses (UPRs) of the endoplasmic reticulum $\left(\mathrm{UPR}^{\mathrm{ER}}\right)$ and mitochondria $\left(\mathrm{UPR}^{\mathrm{MT}}\right)$ and their respective stress-responsive transcription factors HSF1, XBP1, ATF6, and ATFS-1, all with essential roles in the regulation of the $\mathrm{PN}$ (Preissler and Ron 2018; Karagöz et al. 2019; Naresh and Haynes 2019; Needham et al. 2019). In metazoans, these factors merge with the stress-signaling properties of the antioxidant factor SKN-1/NRF2, the insulin-signaling factor DAF-16/FOXO, and the tissue identity factor PHA-4/FOXA to more fully orchestrate organismal survival to diverse environmental and physiological stress conditions and to ensure tissue and compartment specific $\mathrm{PN}$ remodeling to prevent molecular damage. These transcriptional responses are generally coupled with a reduction in protein synthesis through reduced RNA splicing and translation while allowing preferential translation of stress-responsive mRNAs until balance is restored (Harding et al. 2000; Biamonti and Caceres 2009; Shalgi et al. 2013).

In brief, and covered more extensively by Karagöz et al. (2019) and Preissler and Ron (2018), $\mathrm{UPR}^{\mathrm{ER}}$ is regulated by XBP1, ATF6, and ATF4 as separate cis-element response elements to implement these ER-stress-responsive arms (Hetz et al. 2015). XBP1 is activated by the transmembrane endoribonuclease IRE1, which 


\section{R.I. Morimoto}

senses the folding environment inside the ER, whereas activation of the ER-resident transmembrane protein, ATF6, involves relocation from the ER to the Golgi and its subsequent proteolytic cleavage in response to ER stress. Both XBP1 and ATF6 induce genes involved in protein folding, ER-associated protein degradation, and lipid metabolism pathways that are cell protective (Walter and Ron 2011; Chandrahas et al. 2018). Activation of the kinase PERK inhibits protein translation via phosphorylation of the translation initiation factor eIF $2 \alpha$ to prevent the synthesis of nascent chains, and leads to the activation of ATF4, which also induces expression of genes encoding chaperones, components for autophagy, and detoxifying enzymes. Persistent ER stress leads to hyperactivation of IRE1 and induction of the proapoptotic transcription factor CHOP by ATF4, which can trigger cell death to help clear damaged cells (Tabas and Ron 2011). Induction of $\mathrm{UPR}^{\mathrm{MT}}$ by various conditions of cell stress that cause imbalances in mitochondrial function involves ATF5 in mammals that corresponds to ATFS-1 in C. elegans (Schulz and Haynes 2015; Fiorese et al. 2016; Naresh and Haynes 2019). ATFS-1 contains both a mitochondrial targeting sequence and a nuclear localization signal, and under normal cellular conditions is imported into mitochondria and degraded. However, upon conditions of mitochondrial stress, ATFS-1 is directed only to the nucleus to transcribe genes involved in $\mathrm{mi}^{-}$ tochondrial repair mechanisms, including protein folding and detoxification (Haynes et al. 2007; Nargund et al. 2012; Naresh and Haynes 2019).

Oxidative and xenobiotic stresses activate OxR, which controls the expression of redoxregulatory proteins and components of protein degradative pathways mediated the stressresponsive transcription factors NRF1/NFE2L1 and NRF2/NFE2L2 in mammals, which in C. elegans is regulated by SKN-1 (Itoh et al. 1997; An and Blackwell 2003; Radhakrishnan et al. 2010; Blackwell et al. 2015). NRF1 is an ER-resident factor that undergoes regulated proteolytic cleavage upon activation to control expression of genes encoding proteasome subunits and the UPS (Radhakrishnan et al. 2014; Sha and Goldberg 2014). NRF2 in the cytoplasm is negatively regulated by the redox-sensitive ubiquitin ligase KEAP-1, consequently inactivation of KEAP-1 by oxidative and electrophilic stress leads to stabilization and nuclear translocation of NRF2, which in turn induces the expression of antioxidant proteins and detoxification enzymes (Kensler et al. 2007).

The HSR, UPR ${ }^{\mathrm{ER}}$, UPR ${ }^{\mathrm{MT}}$, and OxR pathways overlap both in their input and output indicating that there is substantial cross talk between their signaling components and essential roles to detect cell stress and to provide crossprotective mechanisms. There is increasing evidence that these cell stress responses are not as distinct as previously thought; for example, a subset of cytoplasmic molecular chaperones are activated by ER stress although with different kinetic, and that overexpression of HSF1 in IRE1-deficient cells relieves defects in ER proteostasis, further supporting an interplay between the HSR and the UPR ${ }^{\mathrm{ER}}$ (Liu and Chang 2008). SKN-1 is also activated by the $U P R^{\mathrm{ER}}$ and has a central role in the transcriptional response to ER stress (Hourihan et al. 2016). In C. elegans and human cells, reactive oxygen species generated by the ER or mitochondria sulfenylate a cysteine in IRE1 that inhibits IRE1 activity resulting in a SKN-1 antioxidant stress response. Further, key $\mathrm{UPR}^{\mathrm{ER}}$-signaling factors are involved in the activation of SKN-1 during oxidative stress (Glover-Cutter et al. 2013), and a mitochondrial-to-cytosolic cross talk links mild mitochondrial stress to activation of the HSR and enhancement of the cytosolic folding environment (Kim et al. 2016; Labbadia et al. 2017).

\section{CELL-NONAUTONOMOUS REGULATION OF ORGANISMAL PROTEOSTASIS}

For metazoans, the most important distinction among eukaryotes is tissue organization and coevolution of tissue function for organismal biology. Differences among tissues in the composition and properties of the $\mathrm{PN}$ and risk for exposure to environmental stress could therefore be the basis for distinct molecular responses and risks for tissue-specific proteotoxicity (Guisbert et al. 2013; Bar-Lavan et al. 2016). 
Neurons as a cell type, and the brain as a tissue are maladapted for chronic proteotoxic stress, as exemplified by protein aggregation in Alzheimer's disease (AD), Parkinson's disease (PD), Huntington's disease (HD), amyotrophic lateral sclerosis (ALS), and numerous other neurodegenerative diseases. This has led to speculation that the sensitivity of neurons to protein aggregation and proteotoxicity is a characteristic of postmitotic cells and a compromised HSR.

Despite the abundance and capacity of chaperones and other components of the PN to maintain folding equilibrium, nevertheless, protein conformational diseases are widespread and not limited to only a few tissues as indicated by type II diabetes, multiple myeloma, inclusion body myositis, metabolic diseases, and cystic fibrosis (Morimoto et al. 2011). The conundrum is that molecular chaperones represent a significant fraction of the cellular machinery and are expressed in all subcellular compartments to guide folding and prevent misfolding, and are thought to have excess capacity to buffer against unexpected folding challenges. This position requires that cells have a reserve of chaperones for such emergencies. The counterview is that cells do not have a mechanism to store excess chaperone capacity and therefore the concentration of chaperones in each subcellular compartment is titrated closely, if not precisely, to the immediate cellular needs. Such precise titration, however, would also imply that the folding environment in the cell is delicate with little capacity for a flux of nonnative species. An advantage of this latter model is that the HSR would be under precise regulatory control to adjust the PN rapidly and precisely to specific needs. For this to be compatible with the complex and varying cellular environment, the delicate nature of protein homeostasis would need to be paired with a highly robust stress response that responds rapidly to any flux in protein biogenesis (Fig. 2).

While it is well established that the HSR and other cell stress responses are cell-autonomous in tissue culture cells from Drosophila, vertebrates and in unicellular eukaryotes, at the intact organismal level the HSR and $\mathrm{UPR}^{\mathrm{ER}}$ are cell-nonautonomous. This was initially demonstrated
Cell-Nonautonomous Regulation of Proteostasis

for the HSR in C. elegans that the inducible expression of heat shock genes is regulated cellnonautonomously by specific sensory neurons (Fig. 4; Prahlad et al. 2008). Mutations in the AFD thermosensory or connected interneurons rendered animals deficient selectively for induction of the HSR by heat shock, but did not interfere with the HSF1-dependent induction of heat shock gene expression using a different cell stress condition corresponding to the heavy metal cadmium (Prahlad et al. 2008). The regulation of the HSR involves calcium-activated dense core vesicle (DCV) that is mediated by serotonergic signaling (Prahlad and Morimoto 2011; Tatum et al. 2015). This was further demonstrated using optogenetic activation of thermosensory or serotonergic neurons that activated the HSR in the absence of heat shock stress in nonneuronal somatic tissues, thus providing direct evidence that serotonin is a mediator of tissue communication in the regulation of the HSR (Tatum et al. 2015). Serotonin couples stress sensing and neurotransmitter activity

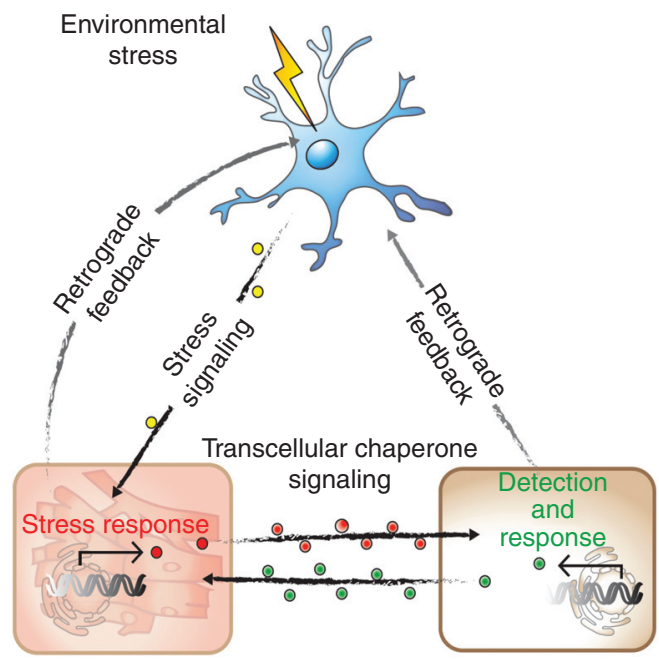

Figure 4. Cell-nonautonomous regulation of organismal proteostasis. Communication between different tissues of Caenorhabditis elegans by which neurons sense heat shock stress and regulate the heat shock response in intestinal and muscle cells is counterbalanced by transcellular chaperone signaling between nonneuronal tissues to sense local proteotoxic stress and to enhance chaperone signaling from a distance. 


\section{R.I. Morimoto}

with movement, fecundity, and the response to food (Tatum et al. 2015). Animals deficient for AFD signaling, while lacking an organismal HSR, remain competent to induce the expression of molecular chaperones of the HSP70 and small HSP family cell-autonomously in response to tissue specific expression of polyQ aggregates (Prahlad and Morimoto 2011). AFD signaling, while conferring centralized control of the HSR, also provides a reversible switch that shifts the animal from cell-nonautonomous to cell-autonomous control. The cell-autonomous induction of chaperone expression in tissues chronically expressing aggregation-prone proteins indicate that C. elegans employs different tissue and signaling networks to respond to acute forms of environmental stress such as heat shock and to the chronic expression of damaged proteins.

The neuronal control of the HSR provides an organism-level coordinated response to various forms of cell stress conditions such as heat shock. If regulation is cell-nonautonomous, this would also suggest that efforts to enhance cell stress responses and proteostasis function at the cellular level may be difficult and perhaps even deleterious at the organismal level. For C. elegans, this offers the intriguing hypothesis that different types of acute and chronic cell stress are sensed by specific neurons or combinations of neurons and sensory pathways. This is supported by the observation that in the absence of AFD neuronal signaling, the HSR reverts from cell-nonautonomous to cell-autonomous when challenged by the expression of protein aggregation (Prahlad and Morimoto 2011).

Another role for neurotransmitters regulating organismal proteostasis is between neurons and muscle cells, across the synaptic junction to influence muscle cell proteostasis by cholinergic signaling (Garcia et al. 2007; Silva et al. 2013). This observation came from a forward genetic screen with C. elegans expressing polyQ proteins in muscle cells, and identification of a mutation in GABA synthesis that compromised muscle cell proteostasis (Garcia et al. 2007). This was supported by a complementary experiment using reverse genetics and a genome-wide RNAi screen that identified a regulator of the acetyl- choline receptor as an enhancer of muscle cell proteostasis (Silva et al. 2011, 2013). The balance of cholinergic signaling affects the flux of $\mathrm{Ca}^{2+}$ in muscle cells and activation of calmodulin and Ca-dependent kinases that enhances the activity of HSF1 and the expression of cytoplasmic chaperones (Silva et al. 2013). What appears to be important is the balance of neuronal signaling in that a reduction of the inhibitory GABAergic signal at the neuromuscular junction causes hyperstimulation of muscle cells at the physiological level, and enhanced aggregation and proteome mismanagement at the cellular level (Garcia et al. 2007).

The observations on cell-nonautonomous control of the HSR extend to the UPR ${ }^{\mathrm{ER}}$ and the $\mathrm{UPR}^{\mathrm{MT}}$ (Durieux et al. 2011; Imanikia et al. 2018; Martínez et al. 2018; Zhang et al. 2018). Perturbation of the mitochondrial electron transfer chain increases life span in both invertebrates and rodents through the activation of the UPR ${ }^{\mathrm{MT}}$ (Liu et al. 2005; Copeland et al. 2009; Durieux et al. 2011). Neuron-targeted disruption of mitochondrial function can lead to cell-nonautonomous activation of the $\mathrm{UPR}^{\mathrm{MT}}$ in nonneuronal tissues in C. elegans (Durieux et al. 2011). These and other studies have proposed a role for a mitokine signal. Recently, Wnt signaling has been shown to communicate mitochondrial stress from the nervous system to peripheral tissues in a serotonin-dependent manner (Zhang et al. 2018). Mild perturbation of the electron transfer chain in Drosophila muscle has a systemic response with beneficial effects on organismal health and life span, which involves repression of insulin signaling (OwusuAnsah et al. 2013). Likewise, in C. elegans, the mild perturbation of subunits of the electron transport chain are beneficial to cellular proteostasis and longevity although in this case involves resetting the cytoplasm by HSF1 (Labbadia et al. 2017). For the $\mathrm{UPR}^{\mathrm{ER}}$, overexpression of active XBP1 in neurons induces the UPR in peripheral tissues (Taylor and Dillin 2013). Induction of the $\mathrm{UPR}^{\mathrm{ER}}$ in nonneuronal tissues during infection by pathogens is mediated by sensory neurons in C. elegans, suggesting an organismal stress response (Sun et al. 2011). Cell-nonautonomous regulation of cellular 
stress responses has also been observed in mice, where overexpression of active XBP1 in proopiomelanocortin neurons leads to activation of the $U P R^{E R}$ in the liver (Williams et al. 2014).

A distinct and complementary form of intertissue communication is between nonneuronal cells and identified as a cell-nonautonomous response to misfolded myosin expressed in muscle cells (Fig. 4). Transcellular chaperone signaling was identified in C. elegans expressing a muscle-specific temperature-sensitive (TS) myosin that misfolds and activates a cell-autonomous HSR in muscle cells and a cell-nonautonomous HSR in cells that do not express myosin (van Oosten-Hawle et al. 2013). The induction of this nonautonomous stress response is regulated by the tissue code factor, PHA4/FOXA, which controls expression of certain molecular chaperones including Hsp90. Consistent with a proposed role for transcellular chaperone signaling, overexpression of the myosin chaperone, Hsp90, in muscle cells restored myosin folding and motility, but as well overexpression of Hsp90 in intestine and neurons also suppressed myosin misfolding. These regulated events had beneficial consequences on organismal proteostasis and stress resilience, suggesting that individual tissues within an organism serve as sensors that respond to local disruptions in proteostasis, and as sentinels to disseminate local stress proteotoxic signals to other tissues to mount an organismal protective response (van OostenHawle and Morimoto 2014). The regulatory factor, PQM-1, is a member of the GATA zincfinger transcription factor family that coordinates the neuronal response with the innate immunity protein, CLEC-41, whereas the intestinal response uses the aspartic protease ASP-12 (O'Brien et al. 2018). Local perturbation of the $\mathrm{PN}$, whether caused by tissue-specific expression of metastable proteins, or by imbalanced expression of chaperones, can therefore be compensated by adjacent tissues in a beneficial transcellular chaperone-signaling response (O’Brien and van Oosten-Hawle 2016).

The tissue-selective HSR and cell-nonautonomous regulation of proteostasis has been observed in a number of other systems, for example with the Drosophila flight motor system
(Kawasaki et al. 2016). The flight motor comprised of specific muscle cells, motor neurons and glia cells are vulnerable to elevated temperatures that cause degeneration, that is prevented by overexpression of the small HSP23 specifically in the flight motor muscle cells. Protection against heat shock stress was observed not only in muscle cells but also neurons and glia cells, consistent with a cell-nonautonomous regulation of the HSR. Related to these observations, intestinal expression of DAF16/FOXO, the effector of the longevity insulin/IGF-1-signaling pathway, can act distantly on muscle to enhance proteostasis (Zhang et al. 2013). Similarly, overexpression of dFOXO/4E-BP in Drosophila muscle influences proteostasis in retina, brain, and adipose tissues, which in turn delays the age-dependent accumulation of protein aggregates (Demontis and Perrimon 2010). While most of our understanding of cell-nonautonomous control of proteostasis comes from studies in invertebrate model organisms, additional support is emerging of a similar process in mammals where circulating factors regulate multiple aspects of physiology (Williams et al. 2014).

Additional support for the cell-nonautonomous control of the PN has come from studies on aging and is addressed more fully below. The decline in the organismal HSR in early adulthood of C. elegans occurs at reproductive maturity and is regulated by signals from the germ stem cells (GSCs) (Shemesh et al. 2013, 2017; Labbadia and Morimoto 2015a). Repression of the HSR involves the placement of the repressive H3K27me3 chromatin marks and reduced chromatin accessibility at the promoters of genes encoding HSPs and the UPR (Labbadia and Morimoto 2015a), thus leaving the adult animal susceptible to stress conditions. The timing of the repression of the HSR at reproductive maturity presumably is selected by energy and resource allocation and represents among the earliest molecular events of aging.

These observations reveal that intertissue communication in metazoans transmits signals from cells and tissues that are stressed perhaps to prime distal tissues as a safeguarding mechanism against impending adverse conditions. 


\section{R.I. Morimoto}

Such systemic stress signals could also have hormetic properties that are beneficial to the organism. This phenomenon is observed in response to protein misfolding within specific tissues and is not restricted only to those cells that directly sense proteotoxic perturbations (van OostenHawle et al. 2013). The relationship between reproduction and inducibility of the HSR observed in animals at reproductive maturity suggests that the age-associated events of cellular failure and loss of tissue robustness during aging is not a random process but rather a highly regulated event, perhaps to ensure that somatic tissues are programmed to decline postreproduction (Labbadia and Morimoto 2015a).

\section{AGING AND THE HEAT SHOCK RESPONSE AND REGULATION OF PROTEOSTASIS NETWORKS}

A striking feature of protein conformational diseases is the relationship between aging and proteostasis decline (Labbadia and Morimoto 2015b; Hipp et al. 2019). Protein aggregation is a common feature of neuropathology in $\mathrm{AD}, \mathrm{PD}, \mathrm{HD}$, and ALS and associated with the expression of A $\beta$ peptide, tau, $\alpha$-synuclein, huntingtin, SOD1, FUS, and TDP-43, respectively (Chiti and Dobson 2006; Jucker and Walker 2018; Dobson et al. 2019). When these proteins, and many others, are expressed within the cellular environment, the aggregation phenotypes are accelerated in aging. The consequence to tissues and organismal health, however, is not just the result of aggregation of a single protein, but rather is an indication of PN failure that is accelerated by certain highly aggregation-prone proteins that cause misfolding and aggregation of other coexpressed metastable proteins (Ciryam et al. 2015; Sormanni and Vendruscolo 2019).

Experimental support for age-dependence of aggregation and proteotoxicity has come primarily from studies using model systems such as C. elegans in which the biology of aging can be directly examined and genetically manipulated. Studies using polyglutamine (polyQ) proteins in body wall muscle cells, intestine, and neurons showed age and polyQ length-dependent aggregation and toxicity, with the polyQ-length tran- sition occurring in the mid-30s similar to what is observed in human polyglutamine expansion diseases (HD, spinocerebellar ataxias, and Kennedy's disease), with aging affecting both aggregation and toxicity (Satyal et al. 2000; Morley et al. 2002; Brignull et al. 2006). Likewise, expression of polyQ-expansion proteins in yeast and Drosophila has contributed a wealth of information on the relationship between the length of the polyQ segment, aggregation propensity, and toxicity (Warrick et al. 1998; Faber et al. 1999; Marsh et al. 2000; Satyal et al. 2000; Parker et al. 2001; Morley et al. 2002; TeixeiraCastro et al. 2011).

The causal relationship with aging was shown using genetic approaches, for example, that the insulin-signaling pathway, a potent regulator of life span, suppresses polyQ aggregation and toxicity dependent upon DAF-16 and HSF1 (Morley et al. 2002; Hsu et al. 2003; Morley and Morimoto 2004; Brignull et al. 2006; TeixeiraCastro et al. 2011). Consistent with these results, genetic knockdown of HSF1 not only strongly promotes aggregation but completely suppresses the longevity benefits of the insulin-signaling pathway. Moreover, life span-enhancing mutations in the insulin-signaling pathway suppress aggregation and cellular dysfunction in C. elegans models of $\mathrm{A} \beta$, polyQ, and ataxin-3 (Morley et al. 2002; Cohen et al. 2006; Teixeira-Castro et al. 2011). This decline in the HSR in aging is associated with aggregation and loss-of-function of endogenous proteins with missense mutations that exhibit TS phenotypes (Ben-Zvi et al. 2009). Expression of expanded polyQ or mutant SOD1 at the permissive temperature enhances misfolding of TS-mutant proteins (Gidalevitz et al. 2006, 2009, 2010). This suggests that the capacity of the cellular machinery to resolve misfolded nonnative proteins is compromised during aging, and that the age-associated decline in the PN is likely a result of the loss in robustness of cell stress responses, leading to the reduced capacity of chaperones and clearance machines (Stadtman 1992; Shamovsky and Gershon 2004; Ben-Zvi et al. 2009).

In addition to the relationship between insulin-signaling and proteostasis, a number of other life span pathways appear to be involved 
including dietary restriction, energy metabolism, and germline signaling in C. elegans, Drosophila, and mice (Mair and Dillin 2008). The effects of dietary restriction on organismal health and longevity in C. elegans are linked to an isoform of SKN-1, the oxidative stress transcription factor that is expressed in a subset of sensory neurons (Bishop and Guarente 2007). Another line of support is the role of SiRT1, the NAD-dependent sirtruin, in the regulation of the HSR (Fig. 3; Westerheide et al. 2009). Attenuation of the HSR involves acetylation of HSF1 in the DNA-binding domain by p300/ $\mathrm{CBP}$, thus preventing occupancy with the HSEs in the promoter region of HSF1-regulated genes (Westerheide et al. 2009; Balchin et al. 2016). The deacetylase, SiRT1, maintains HSF1 in a DNA-binding competent state and thus determines the persistence of HSF1 transcriptional activity (Westerheide et al. 2009). These results show that HSF1 activity can be enhanced using a regulatory override strategy of modulating the cellular levels of NAD or the balance of acetyltransferases and SiRT1, thus prolonging the "youthfulness" benefit of stress resilience promoted by HSF1 and robustness of the HSR.

Organismal health and longevity are also strongly influenced in C. elegans by reproduction (Hsin and Kenyon 1999). The beneficial effects of germline signaling on organismal health was established in development through reproductive maturity and is associated with proteostasis health and decline in the HSR (Ben-Zvi et al. 2009; Shemesh et al. 2013). Signaling from the germline to the somatic tissues for a generalized repression of cell-protective stress responses and loss of organismal stress resilience is because of inhibition of the HSR (Fig. 5; Labbadia and Morimoto 2015a). This is mediated by the inability of HSF1 to bind to the promoters of chaperone genes associated with reduced expression of the jumonji demethylase and corresponding increase in repressive HeK27me3 marks at stress gene promoters (Labbadia and Morimoto 2015a). Either by genetic ablation of germline signaling or by increasing the expression of the jumonji demethylase, the collapse in proteostasis can be prevented thus benefitting cellular function,

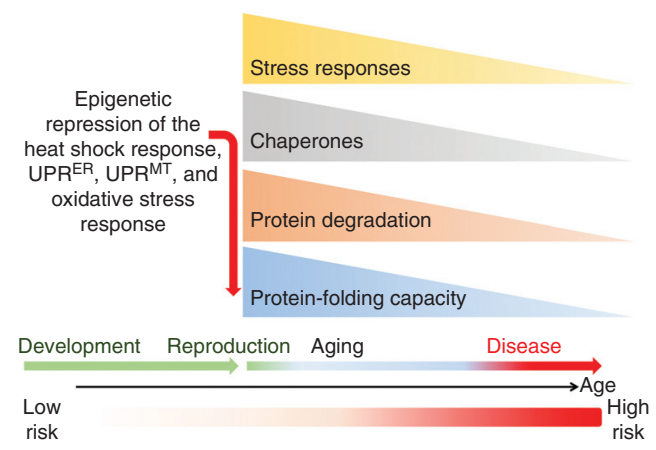

Figure 5. Programmed decline of the heat shock response and other cell stress responses in aging. The timeline of development to reproductive maturity, aging, and risk for disease is indicated as low to high risk. The abrupt decline in cell stress resilience results from the repression of multiple cell stress responses (heat shock response, unfolded protein response [UPR] in the endoplasmic reticulum [ER] and mitochondria and the antioxidant stress response) at reproductive maturity that affects the expression of molecular chaperones, causing accelerated protein aggregation and further compromising protein folding in the cell.

stress resilience, and life span. Removal of the germline also increases life span in Drosophila through modulation of insulin signaling, indicating that regulation of health and longevity by the reproductive system is conserved (Flatt et al. 2008). Enhanced proteostasis and extended life span in animals devoid of a germline therefore relies upon multiple transcription factors, including DAF-16, PHA-4, and SKN-1, in addition to HSF1 (Lin et al. 2001; Lapierre et al. 2011; Steinbaugh et al. 2015).

Is the decline of the HSR and other cell stress responses in aging a common feature of biology? Observations from the brains of old and young rats exposed to hyperthermia showed that the stress-induced DNA-binding competent form of HSF1 was not detected in extracts from old brains but strongly induced in young brains (Shamovsky and Gershon 2004). Consistent with these results, comparison of early and late passage primary human senescent fibroblasts also showed reduced HSF1 DNA-binding activity and heat shock induction of Hsp70 that coincided with reduced levels of SiRT1 (Westerheide et al. 2009). Collectively, these and other 
results support the hypothesis of a decline in adaptive homeostasis in aging (Pomatto and Davies 2017).

\section{PROSPECTUS}

Organismal proteostasis has a level of organizational complexity that builds upon the subcellular and cellular properties of the $\mathrm{PN}$ and communication between tissues by cell-nonautonomous signaling to integrate at the organismal level with the readout being health and longevity. There remains much to be discovered how these signaling processes are organized and identification of components of the PN that communicate or receive the proteostasis status of cells and tissues. How are these signaling processes regulated during normal development and aging, and how do these processes respond to acute and chronic stress? The observations from C. elegans have been useful in providing insights on cell-nonautonomous regulation of cell stress responses such as neuronal control of the HSR and HSF1 and the UPRs. Distinct from neuronal control of the HSR are the effects of germline signaling on the HSR for the programmed decline of proteostasis in aging. This suggests for metazoans an intriguing interplay between neuronal signaling and reproduction.

Regarding aging and proteostasis, evidence for the molecular basis of decline is clear and a question is whether the outcome of poor proteostasis and resulting aggregation and proteotoxicity in other organisms is the result of common underlying mechanisms. The repression of the HSR at reproductive maturity in early adulthood of C. elegans provides evidence for a precise timing of PN failure, which has obvious consequences for protein quality control during aging. However, fecundity in C. elegans occurs over a narrow period in early adulthood in contrast to vertebrate organisms. Nevertheless, similar observations have been made in replicative senescent human fibroblasts that the HSR declines; however, whether the underlying mechanisms are related is to be determined. Likewise, for metazoans, whether all tissues decline simultaneously or that certain tissues are more at risk for failure needs to be addressed. The ability to re- verse age-associated proteostasis decline offers some promise, moreover as there may be multiple nodes of intervention as a strategy to enhance proteostasis functional health in aging and disease.

\section{ACKNOWLEDGMENTS}

These studies were supported by funding provided by the Daniel F. and Ada L. Rice Foundation and the National Institute on Aging. Discussions with many colleagues were invaluable including Anat Ben-Zvi, Tali Gidalevitz, Veena Prahlad, John Labbadia, Jian Li, Laura Bott, Ambre Sala, and Anan Yu.

\section{REFERENCES}

${ }^{*}$ Reference is also in this collection.

Abravaya K, Phillips B, Morimoto RI. 1991a. Attenuation of the heat shock response in HeLa cells is mediated by the release of bound HSF and is modulated by changes in growth and heat shock temperatures. Genes Dev 5: 2117-2127. doi:10.1101/gad.5.11.2117

Abravaya K, Phillips B, Morimoto RI. 1991b. Heat shock induced interactions of heat shock transcription factor and the human HSP70 promoter examined by in vivo footprinting. Mol Cell Biol 11: 586-592. doi:10.1128/ MCB.11.1.586

Abravaya K, Phillips B, Sarge KD, Zimarino V, Morimoto RI. 1991c. In vivo and in vitro studies on the activation and binding of human heat shock transcription factor. In In heat shock (ed. Maresca B, Lindquist S). Springer, New York.

Abravaya K, Myers M, Murphy S, Morimoto RI. 1992. Human heat shock protein HSP70 interacts with HSF, the transcription factor that regulates heat shock gene expression. Genes Dev 6: 1153-1164. doi:10.1101/gad.6.7.1153

Åkerfelt M, Morimoto RI, Sistonen L. 2010. Heat shock factors: Integrators of cell stress, development and lifespan. Nat Rev Mol Cell Biol 11: 545-55. doi:10.1038/ nrm2938

An JH, Blackwell TK. 2003. SKN-1 links C. elegans mesendodermal specification to a conserved oxidative stress response. Genes Dev 17: 1882-1893. doi:10.1101/gad .1107803

Anckar J, Hietakangas V, Denessiouk K, Thiele DJ, Johnson MS, Sistonen L. 2006. Inhibition of DNA binding by differential sumoylation of heat shock factors. Mol Cell Biol 26: 955-964. doi:10.1128/MCB.26.3.955-964.2006

Balch WE, Morimoto RI, Dillin A, Kelly JW. 2008. Adapting proteostasis for disease intervention. Science 319: 916919. doi:10.1126/science.1141448

Balchin D, Hayer-Hartl M, Hartl FU. 2016. In vivo aspects of protein folding and quality control. Science 353: aac4354. doi:10.1126/science.aac4354 
Banerji SS, Theodorakis NG, Morimoto RI. 1984. Heat shock induced translational control of HSP70 and globin synthesis in chicken reticulocytes. Mol Cell Biol 4: 24372448. doi:10.1128/MCB.4.11.2437

Bar-Lavan Y, Shemesh N, Dror S, Ofir R, Yeger-Lotem E, Ben-Zvi A. 2016. A differentiation transcription factor establishes muscle-specific proteostasis in Caenorhabditis elegans. PLoS Genet 12: e1006531. doi:10.1371/journal .pgen.1006531

Batulan Z, Shinder GA, Minotti S, He BP, Doroudchi MM, Nalbantoglu J, Strong MJ, Durham HD. 2003. High threshold for induction of the stress response in motor neurons is associated with failure to activate HSF1. $J \mathrm{Neu}$ rosci 23: 5789-5798. doi:10.1523/jneurosci.23-13-05789 .2003

Bensaude O, Babinet C, Morange M, Jacob F. 1983. Heatshock proteins, first major products of zygotic gene activity in mouse embryo. Nature 305: 331-333. doi:10.1038/ 305331a0

Ben-Zvi A, Miller EA, Morimoto RI. 2009. The collapse of proteostasis represents an early molecular event in C. elegans aging. Proc Natl Acad Sci 106: 14914-14919. doi:10.1073/pnas.0902882106

Biamonti G, Caceres JF. 2009. Cellular stress and RNA splicing. Trends Biochem Sci 34: 146-53. doi:10.1016/j.tibs .2008 .11 .004

* Biebl MM, Buchner J. 2019. Structure, function, and regulation of the Hsp90 machinery. Cold Spring Harb Perspect Biol doi:10.1101/cshperspect.a034017

Bienz M. 1984a. Developmental control of the heat shock response in Xenopus. Proc Natl Acad Sci 81: 3138-3142. doi:10.1073/pnas.81.10.3138

Bienz M. 1984b. Xenopus hsp 70 genes are constitutively expressed in injected oocytes. EMBO J 3: 2477-2483. doi:10.1002/j.1460-2075.1984.tb02159.x

Bishop NA, Guarente L. 2007. Two neurons mediate dietrestriction-induced longevity in C. elegans. Nature 447: 545-549. doi:10.1038/nature05904

Blackwell TK, Steinbaugh MJ, Hourihan JM, Ewald CY, Isik M. 2015. SKN-1/Nrf, stress responses, and aging in Caenorhabditis elegans. Free Radic Biol Med 88: 290-301. doi:10.1016/j.freeradbiomed.2015.06.008

Blake MJ, Fargnoli J, Gershon D, Holbrook NJ. 1991. Concomitant decline in heat-induced hyperthermia and HSP70 mRNA expression in aged rats. Am J Physiol 260: R663-R667. doi:10.1152/ajpregu.1991.260.4.R663

Brignull H, Moore F, Tang S, Morimoto RI. 2006. Polyglutamine proteins at the pathogenic threshold display neuron-specific aggregation in a pan-neuronal C. elegans model. J. Neurosci 26: 7597-7606. doi:10.1523/jneurosci $.0990-06.2006$

Chandrahas VK, Han J, Kaufman RJ. 2018. Coordinating organismal metabolism during protein misfolding in the ER through the unfolded protein response. Curr Top Microbiol Immunol 414: 103-130. doi:10.1007/ 82_2017_41

Chiti F, Dobson CM. 2006. Protein misfolding, functional amyloid, and human disease. Annu Rev Biochem 75: 333366. doi:10.1146/annurev.biochem.75.101304.123901

Chou SD, Prince T, Gong J, Calderwood SK. 2012. mTOR is essential for the proteotoxic stress response, HSF1 activa-
Cell-Nonautonomous Regulation of Proteostasis

tion and heat shock protein synthesis. PLoS ONE 7: e39679. doi:10.1371/journal.pone.0039679

Chu B, Soncin F, Price BD, Stevenson MA, Calderwood SK. 1996. Sequential phosphorylation by mitogen-activated protein kinase and glycogen synthase kinase 3 represses transcriptional activation by heat shock factor-1. J Biol Chem 271: 30847-30857. doi:10.1074/jbc.271.48.30847

Ciryam P, Kundra R, Morimoto RI, Dobson CM, Vendruscolo M. 2015. Supersaturation is a major driving force for protein aggregation in neurodegenerative diseases. Trends Pharmacol Sci 36: 72-77. doi:10.1016/j.tips.2014.12.004

Cohen E, Bieschke J, Perciavalle RM, Kelly JW, Dillin A. 2006. Opposing activities protect against age-onset proteotoxicity. Science 313: 1604-1610. doi:10.1126/science .1124646

Copeland JM, Cho J, Lo T Jr, Hur JH, Bahadorani S, Arabyan T, Rabie J, Soh J, Walker DW. 2009. Extension of Drosophila life span by RNAi of the mitochondrial respiratory chain. Curr Biol 19: 1591-1598. doi:10.1016/j.cub.2009 .08 .016

Dai S, Tang Z, Cao J, Zhou W, Li H, Sampson S, Dai C. 2015. Suppression of the HSF1-mediated proteotoxic stress response by the metabolic stress sensor AMPK. EMBO J 34: 275-293. doi:10.15252/embj.201489062

Demontis F, Perrimon N. 2010. FOXO/4E-BP signaling in Drosophila muscles regulates organism-wide proteostasis during aging. Cell 143: 813-825. doi:10.1016/j.cell.2010 .10 .007

* Deuerling E, Gamerdinger M, Kreft SG. 2019. Chaperone interactions at the ribosome. Cold Spring Harb Perspect Biol doi:10.1101/cshperspect.a033977

* Dobson CM, Knowles TPJ, Vendruscolo M. 2019. The amyloid phenomenon and its significance in biology and medicine. Cold Spring Harb Perspect Biol doi:10.1101/ cshperspect.a033878

Durieux J, Wolff S, Dillin A. 2011. The cell-non-autonomous nature of electron transport chain-mediated longevity. Cell 144: 79-91. doi:10.1016/j.cell.2010.12.016

Ellis RJ, Minton AP. 2006. Protein aggregation in crowded environments. Biol Chem 387: 485-497. doi:10.1515/BC .2006 .064

Faber PW, Alter JR, MacDonald ME, Hart AC. 1999. Polyglutamine-mediated dysfunction and apoptotic death of a Caenorhabditis elegans sensory neuron. Proc Natl Acad Sci 96: 179-184. doi:10.1073/pnas.96.1.179

* Finkbeiner S. 2019. The autophagy lysosomal pathway and neurodegeneration. Cold Spring Harb Perspect Biol doi:10 $.1101 /$ cshperspect.a033993

* Finley D, Prado MA. 2019. The proteasome and its network: Engineering for adaptability. Cold Spring Harb Perspect Biol doi:10.1101/cshperspect.a033985

Fiorese CJ, Schulz AM, Lin YF, Rosin N, Pellegrino MW, Haynes CM. 2016. The transcription factor ATF5 mediates a mammalian mitochondrial UPR. Curr Biol 26: 2037-2043. doi:10.1016/j.cub.2016.06.002

Flatt T, Min KJ, D’Alterio C, Villa-Cuesta E, Cumbers J, Lehmann R, Jones DL, Tatar M. 2008. Drosophila germline modulation of insulin signaling and lifespan. Proc Natl Acad Sci 105: 6368-6373. doi:10.1073/pnas.070 9128105 


\section{R.I. Morimoto}

Freeman BC, Morimoto RI. 1996. The human cytosolic molecular chaperones hsp90, hsp70 (hsc70) and hdj-1 have distinct roles in recognition of a non-native protein and protein refolding. EMBO J 15: 2969-2979. doi:10.1002/j $.1460-2075.1996 . t b 00660 . \mathrm{x}$

Freeman BC, Toft D, Morimoto RI. 1996. Molecular chaperone machines: Chaperone activities of the cyclophilin CyP-40 and the steroid aporeceptor associated protein p23. Science 274: 1718-1720. doi:10.1126/science.274 .5293 .1718

Fujimoto M, Izu H, Seki K, Fukuda K, Nishida T, Yamada S, Kato K, Yonemura S, Inouye S, Nakai A. 2004. HSF4 is required for normal cell growth and differentiation during mouse lens development. EMBO J 23: 4297-4306. doi:10.1038/sj.emboj.7600435

Garcia SM, Casanueva MO, Silva MC, Amaral MD, Morimoto RI. 2007. Neuronal signaling modulates protein homeostasis in Caenorhabditis elegans post-synaptic muscle cells. Genes Dev 21: 3006-3016. doi:10.1101/gad .1575307

Gasch AP, Spellman PT, Kao CM, Carmel-Harel O, Eisen MB, Storz G, Botstein D, Brown PO. 2000. Genomic expression programs in the response of yeast cells to environmental changes. Mol Biol Cell 11: 4241-4257. doi:10 $.1091 / \mathrm{mbc} .11 .12 .4241$

Gidalevitz T, Ben-Zvi A, Ho K, Brignull H, Morimoto RI 2006. Progressive disruption of cellular protein folding in models of polyglutamine diseases. Science 311: 14711474. doi:10.1126/science.1124514

Gidalevitz T, Krupinski T, Garcia SM, Morimoto RI. 2009. Toxicity of mutant SOD1 is directed by protein polymorphisms. PLoS Genet 5: e1000399. doi:10.1371/journal .pgen.1000399

Gidalevitz T, Kikis EA, Morimoto RI. 2010. A cellular perspective on conformational disease: the role of genetic background and proteostasis networks. Curr Opin Struct Biol 20: 23-32. doi:10.1016/j.sbi.2009.11.001

Glover-Cutter KM, Lin S, Blackwell TK. 2013. Integration of the unfolded protein and oxidative stress responses through SKN-1/Nrf. PLoS Genet 9: e1003701. doi:10 .1371/journal.pgen.1003701

Guettouche T, Boellmann F, Lane WS, Voellmy R. 2005. Analysis of phosphorylation of human heat shock factor 1 in cells experiencing a stress. BMC Biochem 6: 4. doi:10 .1186/1471-2091-6-4

Guisbert E, Czyz DM, Richter K, McMullen PD, Morimoto RI. 2013. Identification of a tissue-selective heat shock response regulatory network. PLoS Genet 9: e1003466. doi:10.1371/journal.pgen.1003466

Harding HP, Novoa I, Zhang Y, Zeng H, Wek R, Schapira M, Ron D. 2000. Regulated translation initiation controls stress-induced gene expression in mammalian cells. $\mathrm{Mo}$ Cell 6: 1099-1108. doi:10.1016/S1097-2765(00)00108-8

Haynes CM, Petrova K, Benedetti C, Yang Y, Ron D. 2007. ClpP mediates activation of a mitochondrial unfolded protein response in C. elegans. Dev Cell 13: 467-480. doi:10.1016/j.devcel.2007.07.016

Hensen SM, Heldens L, van Enckevort CM, van Genesen ST, Pruijn GJ, Lubsen NH. 2012. Heat shock factor 1 is inactivated by amino acid deprivation. Cell Stress Chaperones 17: 743-55. doi:10.1007/s12192-012-0347-1
Hetz C, Chevet E, Oakes SA. 2015. Proteostasis control by the unfolded protein response. Nat Cell Biol 17: 829-838. doi:10.1038/ncb3184

Hietakangas V, Ahlskog JK, Jakobsson AM, Hellesuo M, Sahlberg NM, Holmberg CI, Mikhailov A, Palvimo JJ, Pirkkala L, Sistonen L. 2003. Phosphorylation of serine 303 is a prerequisite for the stress-inducible SUMO modification of heat shock factor 1. Mol Cell Biol 23: 2953 2968. doi:10.1128/MCB.23.8.2953-2968.2003

Hipp MS, Kasturi P, Hartl FU. 2019. The proteostasis network and its decline in ageing. Nat Rev Mol Cell Biol doi:10.1038/s41580-019-0101-y

Holmberg C, Hietakangas V, Mikhailov A, Rantanen J, Kallio M, Meinander A, Hellman J, Morrice N, MacKintosh C, Morimoto RI, et al. 2001. The inducible transcriptional activity of heat shock factor 1 is dependent on serine 230 phosphorylation. EMBO J 20: 3800-3810. doi:10.1093/ emboj/20.14.3800

Hourihan JM, Moronetti Mazzeo LE, Fernández-Cárdenas LP, Blackwell TK. 2016. Cysteine sulfenylation directs IRE-1 to activate the SKN-1/Nrf2 antioxidant response. Mol Cell 63: 553-566. doi:10.1016/j.molcel.2016.07.019

Hsin H, Kenyon C. 1999. Signals from the reproductive system regulate the lifespan of C. elegans. Nature 399: 362366. doi:10.1038/20694

Hsu AL, Murphy CT, Kenyon C. 2003. Regulation of aging and age-related disease by DAF-16 and heat-shock factor. Science 300: 1142-1145. doi:10.1126/science.1083701

Imanikia S, Sheng M, Taylor RC. 2018. Cell non-autonomous UPR ${ }^{\mathrm{ER}}$ Signaling. Curr Top Microbiol Immunol 414: 27-43. doi:10.1007/82_2017_38

Itoh K, Chiba T, Takahashi S, Ishii T, Igarashi K, Katoh Y, Oyake T, Hayashi N, Satoh K, Hatayama I, et al. 1997. An Nrf2/small Maf heterodimer mediates the induction of phase II detoxifying enzyme genes through antioxidant response elements. Biochem Biophys Res Commun 236: 313-322. doi:10.1006/bbrc.1997.6943

* Jayaraj GG, Hipp MS, Hartl FU. 2019. Functional modules of the proteostasis network. Cold Spring Harb Perspect Biol doi:10.1101/cshperspect.a033951

* Joutsen J, Sistonen L. 2019. Tailoring of proteostasis networks with heat shock factors. Cold Spring Harb Perspect Biol doi:10.1101/cshperspect.a034066

Jucker M, Walker LC. 2018. Propagation and spread of pathogenic protein assemblies in neurodegenerative diseases. Nat Neurosci 21: 1341-1349. doi:10.1038/s41593-0180238-6

Kallio MJ, Nieminen M, Eriksson JE. 2001. Human inhibitor of apoptosis protein (IAP) survivin participates in regulation of chromosome segregation and mitotic exit. FASEB J 15: 2721-2723. doi:10.1096/fj.01-0280fje

Kampinga HH, Craig EA. 2010. The HSP70 chaperone machinery: J proteins as drivers of functional specificity. Nat Rev Mol Cell Biol 11: 579-592. doi:10.1038/nrm2941

* Karagöz GE, Acosta-Alvear D, Walter P. 2019. The unfolded protein response: Detecting and responding to fluctuations in the protein-folding capacity of the endoplasmic reticulum. Cold Spring Harb Perspect Biol doi:10.1101/ cshperspect.a033886

Kawasaki F, Koonce N, Guo L, Fatima S, Qiu C, Moon MT, Zheng Y, Ordway R. 2016. Small heat shock proteins me- 
diate cell-autonomous and non-autonomous protection in a Drosophila model for environment-stress-induced degeneration. Dis Model Mech 9: 953-964. doi:10.1242/ dmm.026385

Kensler TW, Wakabayashi N, Biswal S. 2007. Cell survival responses to environmental stresses via the Keap1-Nrf2ARE pathway. Annu Rev Pharmacol Toxicol 47: 89-116. doi:10.1146/annurev.pharmtox.46.120604.141046

Kim YE, Hosp F, Frottin F, Ge H, Mann M, Hayer-Hartl M, Hartl FU. 2016. Soluble oligomers of polyQ-expanded huntingtin target a multiplicity of key cellular factors. Mol Cell 63: 951-964. doi:10.1016/j.molcel.2016.07.022

Kline MJ, Morimoto RI. 1997. Repression of the transcriptional activation domain of heat shock factor 1 is modulated by constitutive phosphorylation. Mol Cell Biol 17: 2107-2115. doi:10.1128/MCB.17.4.2107

Knauf U, Newton EM, Kyriakis J, Kingston RE. 1996. Repression of human heat shock factor 1 activity at control temperature by phosphorylation. Genes Dev 10: $2782-$ 2793. doi:10.1101/gad.10.21.2782

Kourtis N, Moubarak RS, Aranda-Orgilles B, Lui K, Aydin IT, Trimarchi T, Darvishian F, Salvaggio C, Zhong J, Bhatt $\mathrm{K}$, et al. 2015. FBXW7 modulates cellular stress response and metastatic potential through HSF1 post-translational modification. Nat Cell Biol 17: 322-332. doi:10.1038/ ncb3121

Krakowiak J, Zheng X, Patel N, Feder ZA, Anandhakumar J, Valerius K, Gross DS, Khalil AS, Pincus D. 2018. Hsf1 and Hsp70 constitute a two-component feedback loop that regulates the yeast heat shock response. eLife 7: e31668. doi:10.7554/eLife.31668

Labbadia J, Morimoto RI. 2015a. Repression of the heat shock response is a programmed event at the onset of reproduction. Mol Cell 59: 639-650. doi:10.1016/j .molcel.2015.06.027

Labbadia J, Morimoto RI. 2015b. The biology of proteostasis in aging and disease. Annu Rev Biochem 84: 435-464. doi:10.1146/annurev-biochem-060614-033955

Labbadia J, Brielmann RM, Neto MF, Lin YF, Haynes CM, Morimoto RI. 2017. Mitochondrial stress restores the heat shock response and prevents proteostasis collapse during aging. Cell Rep 21: 1481-1494. doi:10.1016/j.celrep.2017 .10 .038

* Lam I, Hallacli E, Khurana V. 2019. Proteome-scale mapping of perturbed proteostasis in living cells. Cold Spring Harb Perspect Biol doi:10.1101/cshperspect.a034124

Lapierre LR, Gelino S, Meléndez A, Hansen M. 2011. Autophagy and lipid metabolism coordinately modulate life span in germline-less C. elegans. Curr Biol 21: 1507-1514. doi:10.1016/j.cub.2011.07.042

Li J, Chauve L, Phelps G, Brielmann RM, Morimoto RI. 2016. E2F coregulates an essential HSF developmental program that is distinct from the heat-shock response. Genes Dev 30: 2062-2075. doi:10.1101/gad.283317.116

Li J, Labbadia J, Morimoto RI. 2017. Rethinking HSF1 in stress, development, and organismal health. Trends Cell Biol 12: 895-905. doi:10.1016/j.tcb.2017.08.002

Lin K, Hsin H, Libina N, Kenyon C. 2001. Regulation of the Caenorhabditis elegans longevity protein DAF-16 by insulin/IGF-1 and germline signaling. Nat Genet 28: 139145. doi: $10.1038 / 88850$
Liu Y, Chang A. 2008. Heat shock response relieves ER stress. EMBO J 27: 1049-1059. doi:10.1038/emboj.2008.42

Liu X, Jiang N, Hughes B, Bigras E, Shoubridge E, Hekimi S. 2005. Evolutionary conservation of the clk-1-dependent mechanism of longevity: Loss of mclk1 increases cellular fitness and lifespan in mice. Genes Dev 19: 2424-2434 doi:10.1101/gad.1352905

Mahat DB, Salamanca HH, Duarte FM, Danko CG, Lis JT. 2016. Mammalian heat shock response and mechanisms underlying its genome-wide transcriptional regulation. Mol Cell 62: 63-78. doi:10.1016/j.molcel.2016.02.025

Mair W, Dillin A. 2008. Aging and survival: The genetics of life span extension by dietary restriction. Annu Rev Biochem 77: 727-754. doi:10.1146/annurev.biochem.77.06 1206.171059

Marcuccilli CJ, Mathur SK, Morimoto RI, Miller RJ. 1996. Regulatory differences in the stress response of hippocampal neurons and glial cells after heat shock. J Neurosci 16: 478-485. doi:10.1523/jneurosci.16-02-00478.1996

Marsh JL, Walker H, Theisen H, Zhu YZ, Fielder T, Purcell J, Thompson LM. 2000. Expanded polyglutamine peptides alone are intrinsically cytotoxic and cause neurodegeneration in Drosophila. Hum Mol Genet 9: 13-25. doi:10 $.1093 / \mathrm{hmg} / 9.1 .13$

Martínez G, Khatiwada S, Costa-Mattioli M, Hetz C. 2018. ER proteostasis control of neuronal physiology and synaptic function. Trends Neurosci 41: 610-624. doi:10.1016/ j.tins.2018.05.009

Mathur SK, Sistonen L, Brown IR, Murphy SP, Sarge KD, Morimoto RI. 1994. Deficient induction of human hsp70 heat shock gene transcription in Y79 retinoblastoma cells despite activation of heat shock factor 1. Proc Natl Acad Sci 91: 8695-8699. doi:10.1073/pnas.91.18.8695

McMillan DR, Xiao X, Shao L, Graves K, Benjamin IJ. 1998. Targeted disruption of heat shock transcription factor 1 abolishes thermotolerance and protection against heatinducible apoptosis. J Biol Chem 273: 7523-7528. doi:10.1074/jbc.273.13.7523

Mendillo ML, Santagata S, Koeva M, Bell GW, Hu R, Tamimi RM, Fraenkel E, Ince TA, Whitesell L, Lindquist S. 2015. HSF1 drives a transcriptional program distinct from heat shock to support highly malignant human cancers. Cell 150: 549-562. doi:10.1016/j.cell.2012.06.031

Minsky N, Roeder RG. 2015. Direct link between metabolic regulation and the heat-shock response through the transcriptional regulator PGC-1 $\alpha$. Proc Natl Acad Sci 112: E5669-E5678. doi:10.1073/pnas.1516219112

Morán Luengo T, Mayer MP, Rüdiger SGD. 2019. The HSP70-HSP90 chaperone cascade in protein folding. Trends Cell Biol 29: 164-177. doi:10.1016/j.tcb.2018.10 .004

Morimoto RI. 1998. Inducible transcriptional regulation of heat shock genes: Stress signal and the unfolded protein response. In Molecular chaperones and folding catalysts (ed. Bukau B). Harwood, Reading, UK.

Morimoto RI. 2008. Proteotoxic stress and inducible chaperone networks in neurodegenerative disease and aging. Genes Dev 22: 1427-1438. doi:10.1101/gad.1657108

Morimoto RI. 2011. The heat shock response: Systems biology of proteotoxic stress in aging and disease. Cold Spring Harb Symp Quant Biol 76: 91-99. doi:10.1101/sqb.2012 .76 .010637 


\section{R.I. Morimoto}

Morimoto RI, Driessen AJM, Hegde RS, Langer T. 2011. The life of proteins: The good, the mostly good, and the ugly. Nat Struct Mol Biol 18: 1-4. doi:10.1038/nsmb0111-1

Morley JF, Morimoto RI. 2004. Regulation of longevity in C. elegans by heat shock factor and molecular chaperones. Mol Biol Cell 15: 657-664. doi:10.1091/mbc.e03-07-0532

Morley JF, Brignull H, Weyers J, Morimoto RI. 2002. The threshold for polyglutamine-expansion protein aggregation and cellular toxicity is dynamic and influenced by aging in C. elegans. Proc Natl Acad Sci 99: 10417-10422. doi:10.1073/pnas.152161099

* Naresh NU, Haynes CM. 2019. Signaling and regulation of the mitochondrial unfolded protein response. Cold Spring Harb Perspect Biol doi:10.1101/cshperspect.a033944

Nargund AM, Pellegrino MW, Fiorese CJ, Baker BM, Haynes CM. 2012. Mitochondrial import efficiency of ATFS-1 regulates mitochondrial UPR activation. Science 337: 587-590. doi:10.1126/science. 1223560

* Needham PG, Guerriero CJ, Brodsky JL. 2019. Chaperoning endoplasmic reticulum-associated degradation (ERAD) and protein conformational diseases. Cold Spring Harb Perspect Biol doi:10.1101/cshperspect.a033928

Nillegoda NB, Kirstein J, Szlachcic A, Berynskyy M, Stank A, Stenge F, Arnsburg K, Gao X, Aebersold R, Guilbride DL et al. 2015. Crucial Hsp70 co-chaperone complex unlocks metazoan protein disaggregation. Nature 524: 247-251. doi:10.1038/nature14884

O’Brien D, van Oosten-Hawle P. 2016. Organismal proteostasis: Role of cell-nonautonomous regulation and transcellular chaperone signaling. Genes Dev 28: 1533-1543. doi:10.1101/gad.241125.114

O'Brien D, Jones LM, Good S, Miles J, Vijayabaskar MS, Aston R, Smith CE, Westhead DR, van Oosten-Hawle P. 2018. A PQM-1-mediated response triggers transcellular chaperone signaling and regulates organismal proteostasis. Cell Rep 23: 3905-3919. doi:10.1016/j.celrep.2018 .05 .093

Owusu-Ansah E, Song W, Perrimon N. 2013. Muscle mitohormesis promotes longevity via systemic repression of insulin signaling. Cell 155: 699-712. doi:10.1016/j.cell .2013.09.021

Parker JA, Connolly JB, Wellington C, Hayden M, Dausset J, Neri C. 2001. Expanded polyglutamines in Caenorhabditis elegans cause axonal abnormalities and severe dysfunction of PLM mechanosensory neurons without cell death. Proc Natl Acad Sci 98: 13318-13323. doi:10.1073/pnas 231476398

Pomatto LCD, Davies KJA. 2017. The role of declining adaptive homeostasis in ageing. $J$ Physiol 595: 7275-7309. doi:10.1113/JP275072

Powers ET, Morimoto RI, Dillin A, Kelly JW, Balch WE. 2009. Biological and chemical approaches to diseases of proteostasis deficiency. Annu Rev of Biochem 78: 959991. doi:10.1146/annurev.biochem.052308.114844

Prahlad V, Morimoto RI. 2011. Neuronal circuitry regulates the response of Caenorhabditis elegans to misfolded proteins. Proc Natl Acad Sci 108: 14204-14209. doi:10.1073/ pnas. 1106557108

Prahlad V, Cornelius T, Morimoto RI. 2008. Regulation of the cellular heat shock response in Caenorhabditis elegans by thermosensory neurons. Science 320: 811-814. doi:10 $.1126 /$ science. 1156093
Preissler S, Ron D. 2018. Early events in the endoplasmic reticulum unfolded protein response (UPR). Cold Spring Harb Perspect Biol doi:10.1101/cshperspect.a033894

Radhakrishnan SK, Lee CS, Young P, Beskow A, Chan JY, Deshaies RJ. 2010. Transcription factor Nrf1 mediates the proteasome recovery pathway after proteasome inhibition in mammalian cells. Mol Cell 38: 17-28. doi:10.1016/j molcel.2010.02.029

Radhakrishnan SK, den Besten W, Deshaies RJ. 2014. p97dependent retrotranslocation and proteolytic processing govern formation of active Nrf1 upon proteasome inhibition. eLife 3: e01856. doi:10.7554/eLife.01856

Raychaudhuri S, Loew C, Körner R, Pinkert S, Theis M, Hayer-Hartl M, Buchholz F, Hartl FU. 2014. Interplay of acetyltransferase EP300 and the proteasome system in regulating heat shock transcription factor 1. Cell 156: 975-985. doi:10.1016/j.cell.2014.01.055

Sala AJ, Bott LC, Morimoto RI. 2017. Shaping proteostasis at the cellular, tissue, and organismal level. J Cell Biol 5: 1231-1241. doi:10.1083/jcb.201612111

Satyal S, Schmidt E, Kitagawa K, Sondheimer N, Lindquist S, Morimoto RI. 2000. Polyglutamine aggregates alter protein folding homeostasis in C. elegans. Proc Natl Acad Sci 97: 5750-5755. doi:10.1073/pnas.100107297

Schulz AM, Haynes CM. 2015. UPR ${ }^{\mathrm{mt}}$-mediated cytoprotection and organismal aging. Biochim Biophys Acta 1847: 1448-1456. doi:10.1016/j.bbabio.2015.03.008

Sha Z, Goldberg AL. 2014. Proteasome-mediated processing of Nrf1 is essential for coordinate induction of all proteasome subunits and p97. Curr Biol 24: 1573-1583. doi:10 $.1016 /$ j.cub.2014.06.004

Shalgi R, Hurt JA, Krykbaeva I, Taipale M, Lindquist S, Burge CB. 2013. Widespread regulation of translation by elongation pausing in heat shock. Mol Cell 49: 439452. doi:10.1016/j.molcel.2012.11.028

Shamovsky I, Gershon D. 2004. Novel regulatory factors of HSF-1 activation: Facts and perspectives regarding their involvement in the age-associated attenuation of the heat shock response. Mech Ageing Dev 125: 767-775. doi:10 .1016/j.mad.2004.07.006

Shemesh N, Shai N, Ben-Zvi A. 2013. Germline stem cell arrest inhibits the collapse of somatic proteostasis early in Caenorhabditis elegans adulthood. Aging Cell 12: 814822. doi:10.1111/acel.12110

Shemesh N, Shai N, Meshnik L, Katalan R, Ben-Zvi A. 2017. Uncoupling the trade-off between somatic proteostasis and reproduction in Caenorhabditis elegans models of polyglutamine diseases. Front Mol Neurosci 10: 101. doi:10.3389/fnmol.2017.00101

Shi Y, Mosser DD, Morimoto RI. 1998. Molecular chaperones as HSF1-specific transcriptional repressors. Genes Dev 12: 654-666. doi:10.1101/gad.12.5.654

* Shorter J, Southworth DR. 2019. Spiraling in control: Structures and mechanisms of the Hsp104 disaggregase. Cold Spring Harb Perspect Biol doi:10.1101/cshperspect.a03 4033

Silva MC, Fox S, Thakkar H, Rivera Beam MJ, Amaral MD, Morimoto RI. 2011. A genetic screening strategy identifies novel global regulators of the proteostasis network. PLoS Genet 7: e1002438. doi:10.1371/journal.pgen.10 02438 
Silva MC, Amaral MD, Morimoto RI. 2013. Neuronal reprograming of protein homeostasis by calcium-dependent regulation of the heat shock response. PLoS Genet 9: e1003711. doi:10.1371/journal.pgen.1003711

Sistonen L, Sarge KD, Phillips B, Abravaya K, Morimoto RI 1992. Activation of heat shock transcription factor 2 (HSF2) During hemin induced differentiation of human erythroleukemia cells. Mol Cell Biol 12: 4104-4111. doi:10 $.1128 / \mathrm{MCB} .12 .9 .4104$

* Sormanni P, Vendruscolo M. 2019. Protein solubility predictions using the CamSol method in the study of protein homeostasis. Cold Spring Harb Perspect Biol doi:10.1101/ cshperspect.a033845

Sprang GK, Brown IR. 1987. Selective induction of a heat shock gene in fibre tracts and cerebellar neurons of the rabbit brain detected by in situ hybridization. Brain Res 427: 89-93. doi:10.1016/0169-328X(87)90049-0

Stadtman ER. 1992. Protein oxidation and aging. Science 257: 1220-1224. doi:10.1126/science.1355616

Steinbaugh MJ, Narasimhan SD, Robida-Stubbs S, Moronetti Mazzeo LE, Dreyfuss JM, Hourihan JM, Raghavan P, Operaña TN, Esmaillie R, Blackwell TK. 2015. Lipidmediated regulation of $\mathrm{SKN}-1 / \mathrm{Nrf}$ in response to germ cell absence. eLife 4: e07836. doi:10.7554/eLife.07836

Sun J, Singh V, Kajino-Sakamoto R, Aballay A. 2011. Neuronal GPCR controls innate immunity by regulating noncanonical unfolded protein response genes. Science 332: 729-732. doi:10.1126/science.1203411

Tabas I, Ron D. 2011. Integrating the mechanisms of apoptosis induced by endoplasmic reticulum stress. Nat Cell Biol 13: 184-190. doi:10.1038/ncb0311-184

Tang Z, Dai S, He Y, Doty RA, Shultz LD, Sampson SB, Dai C. 2015. MEK guards proteome stability and inhibits tumor-suppressive amyloidogenesis via HSF1. Cell 160: 729-744. doi:10.1016/j.cell.2015.01.028

Tatum MC, Ooi FK, Chikka MR, Chauve L, Martinez-Velazquez LA, Steinbusch HWM, Morimoto RI, Prahlad V. 2015. Neuronal serotonin release triggers the heat shock response in C. elegans in the absence of temperature increase. Curr Biol 25: 163-174. doi:10.1016/j.cub.2014.11 .040

Taylor RC, Dillin A. 2013. XBP-1 is a cell-nonautonomous regulator of stress resistance and longevity. Cell 153: 1435-1447. doi:10.1016/j.cell.2013.05.042

Teixeira-Castro A, Ailion M, Jalles A, Brignull HR, Vilaça JL, Dias N, Rodrigues P, Oliveira JF, Neves-Carvalho A, Morimoto RI, et al. 2011. Neuron-specific proteotoxicity of mutant Ataxin-3 in C. elegans: Rescue by the DAF-16 and HSF1 pathways. Hum Mol Genet 20: 2996-3009. doi:10 $.1093 / \mathrm{hmg} / \mathrm{ddr} 203$

Theodorakis NG, Morimoto RI. 1987. Post-transcriptional regulation of HSP70 expression in human cells: effects of heat shock, inhibition of protein synthesis and adenovirus infection on translation and mRNA Stability. Mol Cell Biol 7: 4357-4368. doi:10.1128/MCB.7.12.4357

Uversky VN, Oldfield CJ, Dunker AK. 2008. Intrinsically disordered proteins in human diseases: Introducing the
$\mathrm{D}_{2}$ concept. Annu Rev Biophys 37: 215-246. doi:10.1146/ annurev.biophys.37.032807.125924

van Oosten-Hawle P, Morimoto RI. 2014. Organismal proteostasis: Role of cell-nonautonomous regulation and transcellular chaperone signaling. Genes Dev 28: 15331543. doi:10.1101/gad.241125.114

van Oosten-Hawle P, Porter RS, Morimoto RI. 2013. Regulation of organismal proteostasis by transcellular chaperone signaling. Cell 153: 1366-1378. doi:10.1016/j.cell .2013 .05 .015

Vihervaara A, Duarte FM, Lis JT. 2018. Molecular mechanisms driving transcriptional stress responses. Nat Rev Genet 19: 385-397. doi:10.1038/s41576-018-0001-6

Walter P, Ron D. 2011. The unfolded protein response: From stress pathway to homeostatic regulation. Science 334: 1081-1086. doi:10.1126/science. 1209038

Wang Z, Inuzuka H, Zhong J, Wan L, Fukushima H, Sarkar FH, Wei W. 2012. Tumor suppressor functions of FBW7 in cancer development and progression. FEBS Lett 586: 1409-1418. doi:10.1016/j.febslet.2012.03.017

Warrick JM, Paulson HL, Gray-Board GL, Bui QT, Fischbeck KH, Pittman RN, Bonini NM. 1998. Expanded polyglutamine protein forms nuclear inclusions and causes neural degeneration in Drosophila. Cell 93: 939-949. doi:10.1016/S0092-8674(00)81200-3

Westerheide SD, Anckar J, Stevens SM Jr, Sistonen L, Morimoto RI. 2009. Stress-inducible regulation of heat shock factor 1 by the deacetylase SIRT1. Science 323: $1063-$ 1066. doi:10.1126/science.1165946

Williams KW, Liu T, Kong X, Fukuda M, Deng Y, Berglund ED, Deng Z, Gao Y, Liu T, Sohn JW, et al. 2014. Xbp1s in Pomc neurons connects ER stress with energy balance and glucose homeostasis. Cell Metab 20: 471-482. doi:10.1016/j.cmet.2014.06.002

Wu C. 1995. Heat shock transcription factors: Structure and regulation. Annu Rev Cell Dev Biol 11: 441-469. doi:10 .1146/annurev.cb.11.110195.002301

Zelin E, Freeman BC. 2015. Lysine deacetylases regulate the heat shock response including the age-associated impairment of HSF1. J Mol Biol 427: 1644-1654. doi:10.1016/j .jmb.2015.02.010

Zhang P, Judy M, Lee SJ, Kenyon C. 2013. Direct and indirect gene regulation by a life-extending FOXO protein in C. elegans: Roles for GATA factors and lipid gene regulators. Cell Metab 17: 85-100. doi:10.1016/j.cmet.2012.12 .013

Zhang Q, Wu X, Chen P, Liu L, Xin N, Tian Y, Dillin A. 2018. The mitochondrial unfolded protein response is mediated cell-non-autonomously by retromer-dependent Wnt signaling. Cell 174: 870-883.e17. doi:10.1016/j.cell.2018.06 .029

Zou J, Guo Y, Guettouche T, Smith DF, Voellmy R. 1998. Repression of heat shock transcription factor HSF1 activation by HSP90 (HSP90 complex) that forms a stresssensitive complex with HSF1. Cell 94: 471-480. doi:10 $.1016 /$ S0092-8674(00)81588-3 


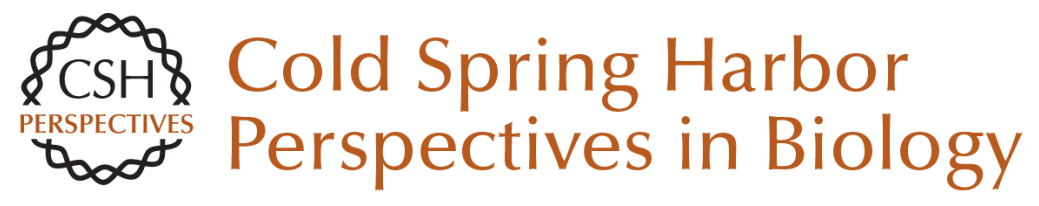

\section{Cell-Nonautonomous Regulation of Proteostasis in Aging and Disease}

Richard I. Morimoto

Cold Spring Harb Perspect Biol 2020; doi: 10.1101/cshperspect.a034074 originally published online April 8, 2019

\section{Subject Collection Protein Homeostasis}

Proteome-Scale Mapping of Perturbed

Proteostasis in Living Cells

Isabel Lam, Erinc Hallacli and Vikram Khurana

Pharmacologic Approaches for Adapting Proteostasis in the Secretory Pathway to

Ameliorate Protein Conformational Diseases Jeffery W. Kelly

Cell-Nonautonomous Regulation of Proteostasis

in Aging and Disease

Richard I. Morimoto

The Autophagy Lysosomal Pathway and

Neurodegeneration Steven Finkbeiner

Functional Modules of the Proteostasis Network Gopal G. Jayaraj, Mark S. Hipp and F. Ulrich Hartl

Protein Solubility Predictions Using the CamSol Method in the Study of Protein Homeostasis Pietro Sormanni and Michele Vendruscolo

Recognition and Degradation of Mislocalized Proteins in Health and Disease

Ramanujan S. Hegde and Eszter Zavodszky

The Nuclear and DNA-Associated Molecular Chaperone Network

Zlata Gvozdenov, Janhavi Kolhe and Brian C. Freeman
The Amyloid Phenomenon and Its Significance in Biology and Medicine

Christopher M. Dobson, Tuomas P.J. Knowles and Michele Vendruscolo

A Chemical Biology Approach to the Chaperome in Cancer--HSP90 and Beyond

Tony Taldone, Tai Wang, Anna Rodina, et al.

Proteostasis in Viral Infection: Unfolding the Complex Virus-Chaperone Interplay Ranen Aviner and Judith Frydman

The Proteasome and Its Network: Engineering for Adaptability Daniel Finley and Miguel A. Prado

Functional Amyloids Daniel Otzen and Roland Riek

Chaperone Interactions at the Ribosome Elke Deuerling, Martin Gamerdinger and Stefan G. Kreft

Mechanisms of Small Heat Shock Proteins Maria K. Janowska, Hannah E.R. Baughman, Christopher N. Woods, et al.

Structure, Function, and Regulation of the Hsp90 Machinery

Maximilian M. Biebl and Johannes Buchner

For additional articles in this collection, see http://cshperspectives.cshlp.org/cgi/collection/

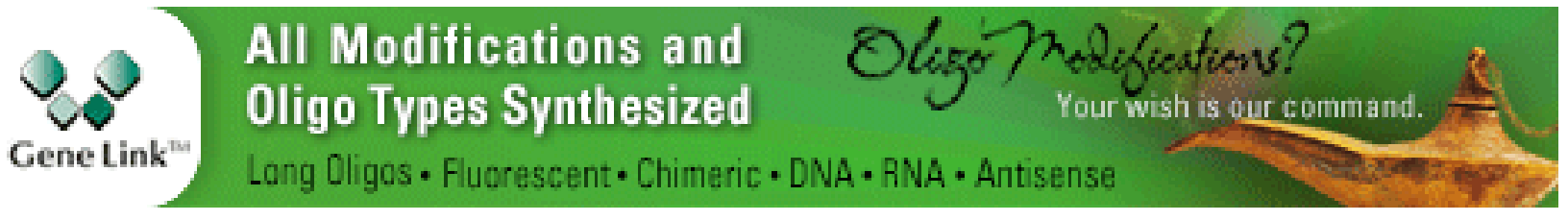


For additional articles in this collection, see http://cshperspectives.cshlp.org/cgi/collection/

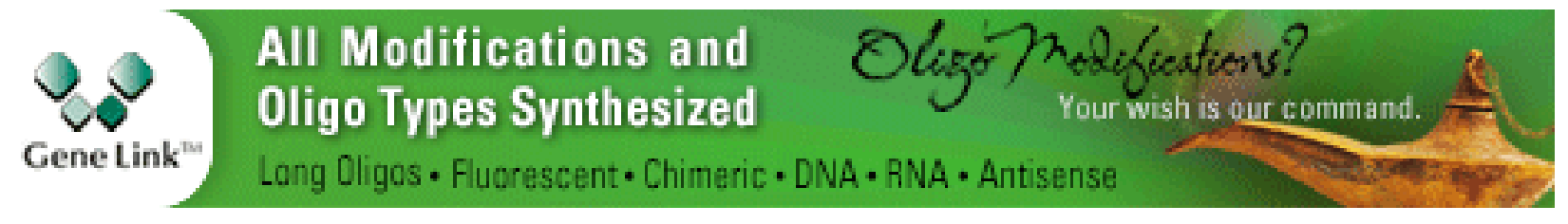

Copyright @ 2020 Cold Spring Harbor Laboratory Press; all rights reserved 